Original article

\title{
Allergen profile of rhinitis and asthma among Iraqi patients
}

\author{
Salwa G. Turki ${ }^{\mathrm{a}}$, Ali H. Ad'hiah ${ }^{\mathrm{b}, *}$, Suad A. Brakhas ${ }^{\mathrm{c}}$, Mohammed R. Atiyah \\ ${ }^{a}$ Department of Basic Science, College of Nursing, University of Baghdad, Baghdad, Iraq \\ ${ }^{\mathrm{b}}$ Tropical-Biological, Research Unit, College of Science, University of Baghdad, Baghdad, Iraq \\ ${ }^{\mathrm{c}}$ Allergy and Immunology Laboratory, Allergy Specialized Center, Alresafa, Baghdad, Iraq
}

A R T I C L E I N F O

\section{Keywords:}

Rhinitis

Asthma

Allergen

IgE

Iraq

\begin{abstract}
A B S T R A C T
Objective: Allergic rhinitis (AR) and bronchial asthma (AS) are two related clinical types of allergic respiratory diseases, and there is a necessity to define both allergies in terms of the associated allergens. Accordingly, a cross-sectional observational study was conducted to examine the allergen profile in AR and AS of Iraqi patients, in whom the data are not well-elaborated.

Methods: During January 2014-April 2017, 653 AR and 521 AS patients were ascertained and their sera were assessed for total and specific IgE.

Results: The 16-45 years was the most encountered age group in AR and AS patients (79.1 and $75.1 \%$, respectively). For total IgE, AS patients at all age groups had a significantly higher level than in AR cases of both genders. However, total IgE level showed no significant variation between age groups with the exception of total AS patients in the age group $>45$ years who had the lowest IgE level (338 $\pm 269 \mathrm{IU} / \mathrm{ml})$. Screening the sera for eight allergen types (animal dander, grasses, house dust, insects, mites, molds, trees and weeds) depicted that molds were the most frequent allergen in AR and AS patients ( 8.7 and 19.6\%, respectively), but mixed sources of allergens were much more frequently encountered.

Conclusion: The age range 16-45 years is an important target for AR and AS. Molds (Alternaria alternate spores) as well as mixed allergens were the mostly encountered types in Iraqi AR and AS patients.
\end{abstract}

\section{Introduction}

The past decades witnessed a considerable prevalence of allergic diseases that have been reported in populations around the globe with a significant impact on the socioeconomic burden. ${ }^{1}$ Allergic rhinitis (AR) and bronchial asthma (AS) are two important clinical types of allergic respiratory diseases that share many pathophysiological features, in which the immune system is misguided against foreign agents that should normally be harmless substances. ${ }^{2}$ Genetic predisposition, exposure to allergens, nutritional condition, existing chronic diseases and acute viral infections are important etiological factors in these two allergies. ${ }^{2,3}$ However, environmental allergens are the most operating factors in genetically predisposed individuals. They are usually classified as indoor (perennial) or outdoor (seasonal). ${ }^{4}$ Indoor aeroallergens (animal dander, dust mite droppings, cockroach droppings and molds) are usually present all year around and can be more harmful than the outdoor allergens. These allergens have been associated with severe and persistent AS. ${ }^{5}$ Outdoor allergens are usually pollen from trees, grasses and weeds, and spores from molds. Each of these has a period of the year in which their levels can rise and fall. Elevated pollen levels observed in spring and summer have been strongly associated with exacerbations of AS in children, ${ }^{6}$ and they also commonly recognized to play a role in AR. ${ }^{7}$

AR appears when allergens contact nasal mucosa and link to IgE antibody in susceptible individuals. This binding leads to a degranulation of mast cells in mucosa and basophils in nasal cavity. The mediators released lead to increased vascular permeability, tissue edema, nasal itching, rhinorrhea (runny nose), mucous secretion, and smooth muscle contraction. ${ }^{8}$ AS is also recognized as an immunologically mediated inflammatory disorder of the airways. It results from a series of interactions within several cells, internal mediators, and neural pathways in the lung. These interactions consequence in allergic inflammations that lead to bronchial hyper-responsiveness, recurrent cough, wheezing, and partially reversible airway obstruction. ${ }^{9}$

Clinically, both AR and AS are triggered by many of the indoor and outdoor allergens and they are interrelated. Epidemiological studies have documented that some children with bronchial AS have associated $\mathrm{AR}$, and $\mathrm{AR}$ children can also develop AS later in their life.

\footnotetext{
Abbreviations: AR, Allergic rhinitis; AS, Asthma; HDM, House dust mite; OR, Odds ratio

* Corresponding author. Tropical-Biological, Research Unit, College of Science, University of Baghdad, Al-Jadriya, Baghdad, Iraq.

E-mail addresses: dr.a.h.adhiah@gmail.com, dr.ahadhiah@sc.uobaghdad.edu.iq (A.H. Ad'hiah).
} 
Furthermore, AR is considered as a major risk factor for triggering AS and increasing the risk of asthmatic attacks. ${ }^{10}$

Accordingly, a cross-sectional observational study was conducted to examine the allergen profile in AR and AS patients who were referred to an allergy center in Baghdad during January 2014-April 2017. Emphases on gender and age distributions were also made. Such findings may aid in establishing a control program for the most common allergens in Iraqi patients, which are important in terms of diagnosis and treatment of AR and AS.

\section{Patients and methods}

\subsection{Study design}

After obtaining the approval of Ethics Committee, a cross-sectional observational study was conducted at the Allergy Specialized Center (Alresafa, Baghdad, Iraq) on patients presented with signs and symptoms suggestive of AR and AS, with the aim to determine the allergen profile in Iraqi patients.

\subsection{Patients}

During January 2014-April 2017, a total of 653 AR (347 males and 306 females) and 521 AS (257 males and 264 females) consecutive patients were referred to the Allergy Specialized Center (Alresafa, Baghdad, Iraq). The patients were clinically examined and diagnosed by the consultant medical staff, and information pertaining to age, gender and allergen type and source was recorded in a data sheet. The diagnosis of AR and AS was based on the guidelines of ARIA (Allergic Rhinitis and their impacts on Asthma) and GINA (Global Initiative for Asthma), respectively. ${ }^{11,12}$ The inclusion criteria for AR were symptoms of nasal obstruction, rhinorrhea, sneezing and nasal pruritus, while those for AS were dyspnea, cough and wheeze. Patients without clear symptoms of AR and AS, pregnant women, or those with chronic respiratory tract infections were excluded from the study. The patients at the time of diagnosis were classified as either AR or AS. The age mean \pm standard deviation (SD) of AR patients was $33.8 \pm 11.9$ years (range: 9-69 years), while for AS patients, it was 30.7 \pm 13.1 years (range: 9-70 years). Both groups of patients were distributed into three age groups; $<16,16-45$ and $>45$ years.

\subsection{IgE level}

The patients were screened for total and specific IgE. Venous blood $(8 \mathrm{ml})$ was drawn from each participant and dispensed in a plain tube. After clotting, the tube was centrifuged (4000 rpm) for $10 \mathrm{~min}$ in a cooled centrifuge $\left(4{ }^{\circ} \mathrm{C}\right)$, and then serum was collected, distributed into aliquots and frozen at $-20{ }^{\circ} \mathrm{C}$ until laboratory assessments (maximum of two weeks). The sera were assessed for total IgE by an ELISA kit (Euroimmun, Germany). The reference or borderline age-adjusted serum levels of IgE were 155 (6-9 years), 199 (10-15 years) and 100 $\mathrm{IU} / \mathrm{ml}$ ( $>16$ years), as depicted in the kit leaflet. A level higher than these values was considered pathological. The sera were also examined for specific IgE using multiplex immunoblot kits (Euroimmun, Germany) that detected 25 inhalation allergens (Table 4). In both assays, the instructions of manufacturer were followed.

\subsection{Statistical analysis}

Information was tabulated in a data sheet of the statistical package SPSS version 19.0, which was used to perform the statistical analyses. Qualitative data were given as numbers and percentage frequencies, and significant differences between frequencies were assessed by Pearson Chi-square test $(\chi 2)$. For a quantitative variable (total IgE level), the original data were tested for normality (KolmogorovSmirnov and Shapiro-Wilk tests), and accordingly, the level was given as median and range. Significant differences between medians were assessed by the nonparametric tests Kruskal-Wallis and Mann-Whitney $U$. A probability $(p)$-value $<0.05$ was considered significant. The disease associated risk (odds ratio; OR) and its $95 \%$ confidence interval (CI) was also calculated for each allergen type in AR patients compared to AS patients. The latter calculations were carried out using the epidemiological software Winpepi version 11.65.

\section{Results}

\subsection{Age and gender}

Age and gender distribution revealed that most AR and AS cases were within the age range $16-45$ years ( 79.1 and $75.1 \%$, respectively), and a similar observation was made when the gender was considered. However, the percentage of AS cases in the age group $<16$ years was significantly higher than that of AR patients $(11.1 v s .6 .0 \%$; $p$-value $<$ 0.01 ), and such high frequency confined to male patients only (16.0 vs. $5.2 \%)$. It was also observed that the percentage of AS female patients in the age group 16-45 years was significantly higher than the corresponding percentage in AS male patients (81.4 vs. 68.5\%; $p$-value < 0.001 ). In terms of $O R$, the age group $16-45$ years was at a greater significant risk to develop AR or AS compared to the age group $<16$ years, and such profile was similar when gender was considered. An increased risk was also recorded in the age group $>45$ years compared to the age group $<16$ years in AR patients, while in AS, only female patients showed a significant increased risk (Table 1).

Table 1

Age and gender distributions of rhinitis and asthma patients.

\begin{tabular}{|c|c|c|c|c|c|c|c|c|c|c|c|c|}
\hline \multirow[t]{2}{*}{ Age Group (Year) } & \multicolumn{6}{|c|}{ Rhinitis } & \multicolumn{6}{|c|}{ Asthma } \\
\hline & $\mathrm{N}$ & $\%$ & $\mathrm{~N}$ & $\%$ & $\mathrm{~N}$ & $\%$ & $\mathrm{~N}$ & $\%$ & $\mathrm{~N}$ & $\%$ & $\mathrm{~N}$ & $\%$ \\
\hline$<16$ & 39 & 6.0 & 18 & 5.2 & 21 & 6.9 & 58 & 11.1 & 41 & 16.0 & 17 & 6.5 \\
\hline $16-45$ & 517 & 79.1 & 270 & 77.8 & 247 & 80.7 & 391 & 75.1 & 176 & 68.5 & 215 & 81.4 \\
\hline$>45$ & 97 & 14.9 & 59 & 17.0 & 38 & 12.4 & 72 & 13.8 & 40 & 15.5 & 32 & 12.1 \\
\hline OR1 $(95 \% \mathrm{CI})$ & \multicolumn{2}{|c|}{$59.85^{* * *}$} & \multicolumn{2}{|c|}{$64.09^{* * *}$} & \multicolumn{2}{|c|}{$56.82^{* * *}$} & \multicolumn{2}{|c|}{$24.01^{* * *}$} & \multicolumn{2}{|c|}{$11.45^{* * *}$} & \multicolumn{2}{|c|}{$63.75^{\text {****}}$} \\
\hline OR2 (95\% CI) & \multicolumn{2}{|c|}{$1.86-4.05$} & \multicolumn{2}{|c|}{$2.16-6.49$} & \multicolumn{2}{|c|}{$1.10-3.36$} & \multicolumn{2}{|c|}{$0.89-1.85$} & \multicolumn{2}{|c|}{$0.60-1.56$} & \multicolumn{2}{|c|}{$1.08-3.70$} \\
\hline
\end{tabular}

Total rhinitis $v s$. Total asthma: $p$-value $<0.01$; Rhinitis males $v$. Asthma males: $p$-value $<0.001$; Rhinitis females $v s$. Asthma females: $p$-value $>0.05$; Rhinitis males $v s$. Rhinitis Females: $p$-value $>0.05$; Asthma males $v$. Asthma females: $p$-value $<0.001$; OR1: Odd ratio of age group 16-45 years $v s$. $<16$ years; OR2: Odd ratio of age group $>45$ years $v s$. $<16$ years; CI: Confidence interval; NS: Not significant ( $p$-value $>0.05$ ); ${ }^{*}, * * *$ : $p$-value $<0.05$ and $<0.001$, respectively. 


\subsection{Total IgE level}

In general, the total serum IgE level median was above the borderline range (pathological level) in all age groups of AR and AS patients of both genders. In addition, total AS patients in all age groups had a significantly higher IgE level than in AR cases of both genders. The exception was female patients at the age groups $<16$ and $>45$ years, in which the differences were not significant. However, the total IgE level showed no significant variation between the age groups of AR or AS patients. AS patients at the age groups $<16$ and $>45$ years were an exception. They were observed to have the highest and lowest level of IgE (517.5 and $305.8 \mathrm{IU} / \mathrm{ml}$, respectively), and the difference was significant ( $p$-value $<0.01$ ). AR male patients in the age group 16-45 years also showed a significant increased level of $\mathrm{IgE}$ compared to the corresponding females (282.9 vs. $189.6 \mathrm{IU} / \mathrm{ml})$, while such difference was restricted to the age group $>45$ years $(335.9 v s .231 .8 \mathrm{IU} / \mathrm{ml})$ of AS patients (Table 2).

\subsection{Allergen profile}

Sera of AR and AS patients were also screened for eight allergen types (animal dander, grasses, house dust, insects, mites, molds, trees and weeds) that included 25 allergen sources. There were some significant differences between the two groups of patients in the reactivity to these allergens. Of importance were molds, which showed a positive reaction in $19.6 \%$ of AS patients, while such frequency in AR patients was $8.7 \%$, and the difference was significant ( $p$-value $<0.001)$. In addition, AS patients positive for at least two of these types or sources (mixed), showed a significantly higher frequency than in AR patients (55.8 vs. 38.8\%; $p$-value $<0.001$ ). Assessing the OR revealed that weeds were associated with a significant increased risk for AR $(\mathrm{OR}=2.30)$, while an increased risk to develop AS was associated with animal dander, insects, molds and allergens of mixed sources (reverse $\mathrm{OR}=2.70,3.50,2.55$ and 2.00, respectively) (Table 3 ).

Distributing AR and AS patients by age groups and allergen type revealed no significant variations, with the exception of mixed type in AS patients, in whom the age group 16-45 years showed a significant increased frequency of positive cases compared to the corresponding age group of AR patients (43.9 vs. $32.6 \%$; $p$-value $<0.001$ ) (data not shown). However, when the allergen source was considered, no significant variation was observed between AR and AS patients, and the frequencies were approximated. The highest frequency was observed for the mold M6 (Alternaria alternate spores) in both groups of patients (10.3 and $12.5 \%$, respectively). However, more than $50 \%$ of AR and AS patients showed a positive reaction for allergens of mixed sources (Table 4).

\section{Discussion}

\subsection{Age and gender}

Both clinical types of allergy (AR and AS) shared the predominance of the age range 16-45 years in total, as well as males and female patients. A tendency of a decreased prevalence in lower and upper age ranges was also observed. Similar findings were also previously reported, and the highest prevalence was reported in AR patients within the age range 20-44 years, and it became less at age greater than 45 years of both genders. ${ }^{13} \mathrm{~A}$ further study confirmed that $11-49$ years is a risk age range for AR and AS. ${ }^{14}$ It has also been reported that AS was more prevalent in males than females during childhood, but at adolescence, it became more sever and prevalent in females. ${ }^{15}$ These observations are consistent with the present data, and the age group $<16$ years showed a significantly increased frequency in AS males compared to females, while at the age group 16-45 years, AS was more frequently observed in females than in males. Such age shift could be attributed to hormonal changes and environmental exposure that placed females at a 
Table 3

Rhinitis and asthma patients distributed according to allergen type.

\begin{tabular}{|c|c|c|c|c|c|c|c|}
\hline \multirow[t]{2}{*}{ Allergen Type } & \multicolumn{2}{|c|}{ Rhinitis $(\mathrm{N}=653)$} & \multicolumn{2}{|c|}{ Asthma $(\mathrm{N}=521)$} & \multirow{2}{*}{$\begin{array}{l}\text { OR }(95 \% \mathrm{CI}) \\
p \text {-value }\end{array}$} & \multirow[t]{2}{*}{ Reverse OR } & \multirow[t]{2}{*}{$p$-value } \\
\hline & $\mathrm{N}$ & $\%$ & $\mathrm{~N}$ & $\%$ & & & \\
\hline Negative & 216 & 33.1 & 2 & 0.4 & & & \\
\hline Animal dander & 20 & 3.0 & 41 & 7.9 & $0.37(0.21-0.64)$ & 2.70 & $<0.001$ \\
\hline Grasses & 12 & 1.8 & 8 & 1.5 & $1.20(0.49-2.96)$ & 0.83 & NS \\
\hline House dust & 11 & 1.7 & 9 & 1.7 & $0.97(0.40-2.37)$ & 1.03 & NS \\
\hline Insects & 4 & 0.6 & 11 & 2.1 & $0.29(0.09-0.90)$ & 3.50 & $<0.05$ \\
\hline Mites & 41 & 6.3 & 41 & 7.9 & $0.78(0.50-1.23)$ & 1.28 & NS \\
\hline Molds & 57 & 8.7 & 102 & 19.6 & $0.39(0.28-0.56)$ & 2.55 & $<0.001$ \\
\hline Trees & 0 & 0.0 & 2 & 0.4 & $0.16(0.01-3.31)$ & 6.29 & NS \\
\hline Weeds & 39 & 6.0 & 14 & 2.7 & $2.30(1.24-4.28)$ & 0.43 & $<0.01$ \\
\hline Mixed & 253 & 38.8 & 291 & 55.8 & $0.50(0.40-0.63)$ & 2.00 & $<0.001$ \\
\hline
\end{tabular}

OR: Odds ratio; CI: Confidence interval; NS: Not significant ( $p$-value $>0.05$ ).

higher risk of AS after the age 16 years and up to 45 years. ${ }^{16}$ Additionally, most prospective studies in adults showed a higher incidence of AS in females than males. ${ }^{17}$ It has also been recently reviewed that the ovarian hormone estrogen enhances $\mathrm{T}$ helper-2-mediated airway inflammation, while testosterone (male hormone) decreases such response in AS patients. In addition, females were observed to have increased IL-17A-mediated airway inflammations compared to males. ${ }^{18}$ The increase of AS prevalence in females compared to males has been reported to be maintained until around the time of menopause, at which a decrease in AS prevalence was noted in women. ${ }^{19}$ Therefore, shifts in AS prevalence based on gender probably coincide with changes in sex hormones and suggest that these hormones modulate airpathway reactions to allergens that are associated with AS pathogenesis.

\subsection{Total IgE level}

IgE is a unique immunoglobulin that plays a central role in pathophysiology of acute and chronic allergic reactions. ${ }^{20}$ In this study, the majority of patients were presented with a high level of IgE that exceeded the reference range; an observation that confirms its significant role in pathogenesis of both allergies, especially AS, in which the level was significantly increased compared to AR. Such significant difference between AR and AS patients could not be elucidated, but a similar observation has also been made in Spanish and Indian patients. ${ }^{21,22}$ With respect to age, although the differences were not significant in AR but not AS, the present results also share that AR and AS patients younger than 16 years have higher serum levels of $\operatorname{IgE}$ compared to adults at the age range 16-45 years. ${ }^{23}$ However, at ages older than 45 years, the IgE tended to have a decreased serum level, and the difference was significant in AS compared to younger ages. Such findings came to confirm that IgE shows a decreased level as age is progressed after 45 years in AR and AS patients. ${ }^{24}$ However, in a more recent large cohort study (6,370 allergic patients), conflicting results were presented and total IgE levels showed no decrease with age advancement. The highest peak of total IgE was observed in the age group 28-30 years, and in addition, there was an increasing trend in total IgE during aging that peaked at the age group $>85$ years, especially in females. ${ }^{25}$

\subsection{Allergen profile}

The study demonstrated that molds were the most frequent

Table 4

Rhinitis and asthma patients distributed according to allergen source.

\begin{tabular}{|c|c|c|c|c|c|c|c|}
\hline \multicolumn{3}{|l|}{ Allergen } & \multicolumn{2}{|c|}{ Rhinitis (N = 437) } & \multicolumn{2}{|c|}{ Asthma (N = 519) } & \multirow[t]{2}{*}{$p$-value } \\
\hline Type & Code & Source & $\mathrm{N}$ & $\%$ & $\mathrm{~N}$ & $\%$ & \\
\hline \multirow[t]{5}{*}{ Animal dander } & e1 & Cat & 3 & 0.7 & 11 & 2.1 & NS \\
\hline & $\mathrm{e} 2$ & Dog epithelium & 0 & 0 & 1 & 0.2 & \\
\hline & e3 & Horse & 0 & 0 & 1 & 0.2 & \\
\hline & e5 & Dog dander & 0 & 0 & 1 & 0.2 & \\
\hline & e17 & Camel & 17 & 3.9 & 27 & 5.2 & \\
\hline \multirow[t]{2}{*}{ Grasses } & G12 & Cultivated rye & 5 & 1.1 & 6 & 1.2 & NS \\
\hline & G6 & Timothy grass & 7 & 1.6 & 2 & 0.4 & \\
\hline \multirow[t]{2}{*}{ House dust } & $\mathrm{H} 1$ & House dust greer & 3 & 0.7 & 7 & 1.3 & NS \\
\hline & $\mathrm{H} 2$ & Hollister-stir house dust & 8 & 1.8 & 2 & 0.4 & \\
\hline Insects & I6 & Cockroach, German & 4 & 0.9 & 11 & 2.1 & NS \\
\hline \multirow[t]{2}{*}{ Mites } & D1 & Dermatophagoides pteronyssinus & 24 & 5.5 & 14 & 2.7 & NS \\
\hline & D2 & Dermatophagoides farino & 17 & 3.9 & 27 & 5.2 & \\
\hline \multirow[t]{5}{*}{ Molds } & M1 & Penicillium notatum spores & 0 & 0 & 1 & 0.2 & NS \\
\hline & M2 & Cladosporium herbarum spores & 5 & 1.1 & 9 & 1.7 & \\
\hline & M3 & Aspergillus fumigates spores & 7 & 1.6 & 23 & 4.4 & \\
\hline & M5 & Candida albicans spores & 0 & 0 & 4 & 0.8 & \\
\hline & M6 & Alternaria alternate spores & 45 & 10.3 & 65 & 12.5 & \\
\hline \multirow[t]{5}{*}{ Trees } & $\mathrm{T} 2$ & Alder & 0 & 0.0 & 0 & 0.0 & NS \\
\hline & $\mathrm{T} 3$ & Birch & 0 & 0.0 & 0 & 0.0 & \\
\hline & T7 & Oak & 0 & 0 & 1 & 0.2 & \\
\hline & T8 & Elm & 0 & 0.0 & 0 & 0.0 & \\
\hline & T9 & Olive tree & 0 & 0 & 1 & 0.2 & \\
\hline \multirow[t]{3}{*}{ Weeds } & W1 & Common ragweed & 1 & 0.2 & 1 & 0.2 & NS \\
\hline & W6 & Mugwort & 0 & 0 & 3 & 0.6 & NS \\
\hline & W10 & Chenopodium & 38 & 8.7 & 10 & 1.9 & \\
\hline Total Mixed & Mixed & & 253 & 57.9 & 291 & 56.1 & NS \\
\hline
\end{tabular}

NS: Not significant (p-value $>0.05$ ). 
allergens in AS and AR patients, and M6 (Alternaria alternate spores) dominated the frequency in both allergies. In Saudi Arabia, it was also revealed that Alternaria spores are prevalent as a major outdoor allergen, and the authors suggested that airborne Alternaria can be a potential allergic sensitizer for AR and AS in susceptible individuals. ${ }^{26}$ The same Saudi group evaluated the prevalence of positive skin tests to mold allergens in different Arabic geographical regions (Saudi Arabia, United Arab Emirates, and Sudan). Sensitization to mold allergens showed different prevalence depending on the region investigated, but sensitizations to Cladosporium spp., Aspergillus fumigatus, and Alternaria were more frequent in Khartoum city of Sudan compared to other regions. Ulocladium and Penicillium were less prevalent but they showed a great variation between the regions studied. ${ }^{27}$ However, in nearby region (Kuwait), most allergic patients (AR and AS) became sensitized to Salsola imbricata pollens, which were considered as a predominant cause of respiratory allergies. ${ }^{28}$ In Jordan, more than $40 \%$ of AR patients were sensitized to grasses mix, thistleweed and olive tree pollens. ${ }^{29}$ East to Iraq (Iran), it has been reported that house dust mites (HDMs), molds, animal dander, weeds, trees, and grass pollen were the most common allergens in AR and AS patients. ${ }^{30}$ In Turkey (northern Iraq), Phleum pratense, Dermatophagoides pteronyssinus and Artemisia vulgaris allergens were found to be adequate for the identification of at least $95 \%$ of the sensitized AR and AS subjects in Ankara. ${ }^{31}$ With respect to Iraq, Goronfolah has reviewed that data about atopy are limited with just three published studies. In the city of Baquba, the most common sensitizers were HDMs, Bermuda grass, and mixed grasses. In Tikrit city, the most notable sensitizations were for Bermuda grass, grass mix, molds, $D$ pte, and $D$ far. Finally, HDMs and grass pollen were the most common allergens in Mosul city. ${ }^{7}$

It is obvious that the allergens show different profiles in local and regional studies. Geographical and climate changes could affect the sensitization profiles by altering the allergen distribution, amount, germination rate and allergenicity. ${ }^{32}$ Gender and age may also modify the sensitization pattern. ${ }^{13,17}$

\section{Conclusion}

The age range 16-45 years is an important target for AR and AS. Molds (Alternaria alternate spores) as well as mixed allergens were the most encountered types in Iraqi patients living in Baghdad. Gender and age are also important factors than can interfere with the presentation of both allergies. This study is probably the first that defined a largescaled types and source of allergens in Iraqi AR and AS patients, and can aid in planning of treatment strategies for the management of both allergies. However, seasonal variation of allergens was not determined and may represent a limitation of study.

\section{Funding sources}

This research did not receive any specific grant from funding agencies in the public, commercial, or not-for-profit sectors.

\section{Declaration of competing interest}

None.

\section{Acknowledgment}

The authors appreciate the kind help and cooperation of the medical staff at the Allergy Specialized Center in Alresafa, Baghdad.

\section{References}

1. Pawankar R. Allergic diseases and asthma: a global public health concern and a call to action. World Allergy Organ J. 2014;7(1):1-3. https://doi.org/10.1186/1939-45517-12.
2. Khan DA. Allergic rhinitis and asthma: epidemiology and common pathophysiology. Allergy Asthma Proc. 2014;35(5):357-361. https://doi.org/10.2500/aap.2014.35. 3794.

3. Edwards MR, Strong K, Cameron A, Walton RP, Jackson DJ, Johnston SL. Viral infections in allergy and immunology: how allergic inflammation influences viral infections and illness. J Allergy Clin Immunol. 2017;140(4):909-920. https://doi.org/ 10.1016/j.jaci.2017.07.025.

4. Singh M, Hays A. Indoor and outdoor allergies. Prim Care Clin Off Pract. 2016;43(3):451-463. https://doi.org/10.1016/j.pop.2016.04.013.

5. Pomés A, Chapman MD, Wünschmann S. Indoor allergens and allergic respiratory disease. Curr Allergy Asthma Rep. 2016;16(6):43. https://doi.org/10.1007/s11882016-0622-9.

6. Tham R, Dharmage SC, Taylor PE, et al. Outdoor fungi and child asthma health service attendances. Pediatr Allergy Immunol. 2014;25(5):439-449. https://doi.org/ 10.1111/pai.12257.

7. Goronfolah L. Aeroallergens, atopy and allergic rhinitis in the Middle East. Eur Ann Allergy Clin Immunol. 2016;48(1):5-21http://www.ncbi.nlm.nih.gov/pubmed/ 26808447, Accessed date: 10 September 2018.

8. Eifan AO, Durham SR. Pathogenesis of rhinitis. Clin Exp Allergy. 2016;46(9):1139-1151. https://doi.org/10.1111/cea.12780.

9. Poon AH, Eidelman DH, Martin JG, Laprise C, Hamid Q. Pathogenesis of severe asthma. Clin Exp Allergy. 2012;42(5):625-637. https://doi.org/10.1111/j.13652222.2012.03983.x.

10. Kariyawasam HH, Rotiroti G. Allergic rhinitis, chronic rhinosinusitis and asthma: unravelling a complex relationship. Curr Opin Otolaryngol Head Neck Surg. 2013;21(1):79-86. https://doi.org/10.1097/MOO.0b013e32835ac640.

11. Brożek JL, Bousquet J, Baena-Cagnani CE, et al. Allergic rhinitis and its impact on asthma (ARIA) guidelines: 2010 revision. $J$ Allergy Clin Immunol. 2010;126(3):466-476. https://doi.org/10.1016/j.jaci.2010.06.047.

12. Becker AB, Abrams EM. Asthma guidelines: the Global Initiative for Asthma in relation to national guidelines. Curr Opin Allergy Clin Immunol. 2017;17(2):99-103. https://doi.org/10.1097/ACI.0000000000000346.

13. Cazzoletti L, Ferrari M, Olivieri M, et al. The gender, age and risk factor distribution differs in self-reported allergic and non-allergic rhinitis: a cross-sectional populationbased study. Allergy Asthma Clin Immunol. 2015;11(1):36. https://doi.org/10.1186/ s13223-015-0101-1.

14. Rasheed $\mathrm{SMH}, \mathrm{Al}$-joboury $\mathrm{H}, \mathrm{Al}$-hasnawi SM, Ch MBB, College MS, Medicine $\mathrm{O}$. Prevalence of aeroallergens in patients with symptoms of respiratory allergy in Alnajaf province. $J$ Univ Kerbala. 2016;14(4):50-58https://www.iasj.net/iasj?func = fulltext\&aId $=118312$.

15. Almqvist C, Worm M, Leynaert B. Working group of GA2LEN WP 2.5 Gender. Impact of gender on asthma in childhood and adolescence: a GA2LEN review. Allergy. 2008:47-57. https://doi.org/10.1111/j.1398-9995.2007.01524.x 0(0).

16. van den Berge M, Heijink HI, van Oosterhout AJM, Postma DS. The role of female sex hormones in the development and severity of allergic and non-allergic asthma. Clin Exp Allergy. 2009;39(10):1477-1481. https://doi.org/10.1111/j.1365-2222.2009. 03354.x.

17. Leynaert B, Sunyer J, Garcia-Esteban R, et al. Gender differences in prevalence, diagnosis and incidence of allergic and non-allergic asthma: a population-based cohort. Thorax. 2012;67(7):625-631. https://doi.org/10.1136/thoraxjnl-2011-201249.

18. Fuseini H, Newcomb DC. Mechanisms driving gender differences in asthma. Curr Allergy Asthma Rep. 2017;17(3):19. https://doi.org/10.1007/s11882-017-0686-1.

19. Yung JA, Fuseini H, Newcomb DC. Hormones, sex, and asthma. Ann Allergy Asthma Immunol. 2018;120(5):488-494. https://doi.org/10.1016/j.anai.2018.01.016.

20. Navinés-Ferrer A, Serrano-Candelas E, Molina-Molina G-J, Martín M. IgE-related chronic diseases and anti-IgE-based treatments. J Immunol Res. 2016;2016:1-12. https://doi.org/10.1155/2016/8163803.

21. Alvarez-Puebla MJ, García-Figueroa BE, Tabar-Purroy AI, Olaguibel-Rivera JM. Discriminant analysis in allergic rhinitis and asthma: methacholine dose-response slope allows a good differentiation between mild asthma and rhinitis. Respir Med. 2003;97(1):30-36. https://doi.org/10.1053/rmed.2002.1420.

22. Deo SS, Mistry KJ, Kakade AM, Niphadkar PV. Relationship of total IgE, specific IgE, skin test reactivity and eosinophils in Indian patients with allergy. J Indian Acad Clin Med. 2010;11(4):265-271.

23. Lee KS, Yu J, Shim D, et al. Local Immune Responses in Children and Adults with Allergic and Nonallergic Rhinitis. In: Zhang L, ed. PLoS One. vol.11. 2016; 2016e0156979https://doi.org/10.1371/journal.pone.0156979 6.

24. Matsui EC, Sampson HA, Bahnson HT, et al. Allergen-specific IgE as a biomarker of exposure plus sensitization in inner-city adolescents with asthma. Allergy. 2010;65(11):1414-1422. https://doi.org/10.1111/j.1398-9995.2010.02412.x.

25. De Amici M, Ciprandi G. The age impact on serum total and allergen-specific IgE. Allergy Asthma Immunol Res. 2013;5(3):170. https://doi.org/10.4168/aair.2013.5.3. 170.

26. Hasnain SM, Al-Frayh A, Gad-El-Rab MO, Al-Sedairy S. Airborne alternaria spores: potential allergic sensitizers in Saudi Arabia. Ann Saudi Med. 1998;18(6):497-501http://www.ncbi.nlm.nih.gov/pubmed/17344715, Accessed date: 10 September 2018.

27. Hasnain SM, Al-Frayh AR, Subiza JL, et al. Sensitization to indigenous pollen and molds and other outdoor and indoor allergens in allergic patients from Saudi Arabia, United Arab Emirates, and Sudan. World Allergy Organ J. 2012;5(6):59-65. https:// doi.org/10.1097/WOX.0b013e31825a73cd.

28. Al-Dowaisan A, Fakim N, Khan MR, et al. Salsola pollen as a predominant cause of respiratory allergies in Kuwait. Ann Allergy Asthma Immunol. 2004;92(2):262-267. https://doi.org/10.1016/S1081-1206(10)61558-X.

29. Aburuz S, Bulatova N, Tawalbeh M. Skin prick test reactivity to aeroallergens in Jordanian allergic rhinitis patients. East Mediterr Health $J$. 
2011;17(7):604-610http://www.ncbi.nlm.nih.gov/pubmed/21972485, Accessed date: 10 September 2018.

30. Farrokhi S, Gheybi MK, Movahed A, et al. Common aeroallergens in patients with asthma and allergic rhinitis living in southwestern part of Iran: based on skin prick test reactivity. Iran J Allergy, Asthma Immunol. 2015;14(2):133-138http://www.ncbi. nlm.nih.gov/pubmed/25780879, Accessed date: 10 September 2018.
31. Comert S, Demir AU, Karakaya G, Kalyoncu AF. Minimum prick test panel for adult patients with asthma and rhinitis in Ankara, Turkey. $J$ Asthma. 2014;51(4):417-422. https://doi.org/10.3109/02770903.2013.878846.

32. Reid CE, Gamble JL. Aeroallergens, allergic disease, and climate change: impacts and adaptation. EcoHealth. 2009;6(3):458-470. https://doi.org/10.1007/s10393-0090261-x. 